\title{
Social Determinants of Poor Management of Type 2 Diabetes Among the Insured
}

\author{
Minal R. Patel ${ }^{1}$ (D) \\ Accepted: 26 October 2020 / Published online: 5 November 2020 \\ (C) Springer Science+Business Media, LLC, part of Springer Nature 2020
}

\begin{abstract}
Purpose of Review Even with insurance coverage increasing over time among the population with diabetes, a large proportion continues to have poorly controlled disease. The purpose of this narrative literature review is to describe the social determinants of poor management of type 2 diabetes among the insured population and illustrate drivers of poor outcomes beyond insurance coverage.

Recent Findings Despite the provision of health insurance, social determinants play a significant role in shaping diabetes outcomes, especially for economic instability (employment, out-of-pocket expenses associated with diabetes management), food insecurity, education and literacy, access to quality health care (health systems designed to effectively manage chronic disease), neighborhood and the built environment (segregated neighborhoods, socioeconomic conditions of communities, housing), and social and community context (discrimination, social support).

Summary Multiple social determinants shape poor diabetes outcomes among the insured. These determinants are now being further exacerbated by the COVID-19 pandemic, which has created the worst economic crisis for US families since the Great Depression. The evidence of this review points to the imperative need for more multilevel intervention approaches to address these determinants in the management of diabetes.
\end{abstract}

Keywords Social determinants $\cdot$ Diabetes $\cdot$ Health insurance $\cdot$ Outcomes

\section{Introduction}

Diabetes impacts 1 in 10 Americans in the United States (U.S.) and is among the leading causes of death and disability [1]. Diabetes is the leading cause of kidney failure, lower limb amputations, and adult-onset blindness, and the seventh leading cause of death in the U.S. [1-3] The average medical expenditures among people with diagnosed diabetes are 2.3 times higher than what expenditures would be in the absence of diabetes [4]. In 2017, the total cost of diagnosed diabetes in the U.S. was $\$ 327$ billion, which includes $\$ 237$ billion in direct medical costs and $\$ 90$ billion in reduced productivity [4]. Much of these clinical and economic consequences of

This article is part of the Topical Collection on Diabetes Epidemiology

Minal R. Patel

minalrp@umich.edu

1 Department of Health Behavior and Health Education, University of Michigan School of Public Health, 1415 Washington Heights, SPH 1, Room 3810, Ann Arbor, MI 48109-2029, USA diabetes can be avoided with effective management of the condition. However, one-third to nearly half of people with diabetes still do not meet general targets for glycemic, blood pressure, or cholesterol control [5].

Health insurance provides protections from significant financial risk associated with the costs of health and medical care. It has been shown to be a strong indicator of diagnosis, linkage, and achievement of markers indicating diabetes control [6]. The 2010 passage of the Affordable Care Act (ACA) significantly increased access to care for many individuals with diabetes, with coverage rates at $90 \%$ for people 18-64 in 2016, and near universal coverage for those greater than 65 years [5]. However, even with insurance coverage increasing over time among the population with diabetes post-ACA, a large proportion continues to have poorly controlled disease [7]. Cost-related non-adherence (CRN) rates among diabetes-insured dual-eligible patients (qualifying for both Medicare and Medicaid) and patients between 50 and 65 of age remain high, around $20 \%$, even after the ACA $[8,9]$. This suggests that for the insured population with diabetes, there are factors 
beyond insurance coverage and the standard provision of medical treatment that drive poorly controlled disease.

Social determinants of health are conditions in the environment, including patterns of social engagement, in which people are born, live, learn, work, play, worship, and age that affect a wide range of health, functioning, and quality-of-life outcomes and risks [10]. Social determinants are also major drivers of health inequities observed in diabetes morbidity and mortality within population subgroups [11]. In recent years, the Standard for Medical Care in Diabetes guidelines by the American Diabetes Association have included recommendations for tailoring treatment for social context, acknowledging the significant role that social determinants contribute in shaping diabetes outcomes [5].

The purpose of this narrative literature review is to describe the social determinants of poor management of type 2 diabetes among the insured population in order to provide a more nuanced picture of the drivers of poor outcomes beyond insurance coverage. This review selects domains from the Healthy People 2020 Framework for Social Determinants of Health [10], and draws on the existing empirical literature that focuses on people diagnosed and managing diabetes.

\section{Economic Vulnerability}

Economic vulnerability impacts poor diabetes management among the insured through mechanisms that can be explained by employment and out-of-pocket (OOP) expenses associated with health insurance coverage.

In a systematic review by Breton and colleagues (2013) focused on diabetes and the ability to work, several findings shed light on how employment may lead to economic vulnerability and in turn poor diabetes outcomes. They found consistent findings across studies demonstrating that employees with diabetes may stop working prematurely and may experience unemployment [12]. Further, there is consistent evidence across studies with high methodological quality that diabetes complications impact increased absenteeism, productivity, and early retirement [12].

Insurance in itself can fuel economic instability among those managing diabetes. Regardless of type of health insurance, uptake of diabetes treatment and management is highly sensitive to OOP expenses associated with insurance (e.g., copays, premiums, deductibles) [13]. The OOP expenses consumers face with diabetes treatments are largely driven by their list price [14]. One example is the cost of insulin. One study observed that patient OOP expenses for insulin doubled over a 10-year period [15], with a simultaneous trend of the average list price nearly tripling in that period of time [13]. Further, frequent formulary changes or exclusions of treatments increase OOP to people with diabetes [14]. In recent years, there has been growing enrollment in high-deductible health plans (HDHPs) among working age adults [16]. For vulnerable populations, especially low-income patients, HDHPs may present barriers to care and increases in adverse outcomes and costs [17]. Wharam et al. showed that lowincome people with diabetes and HDHPs had increased high severity emergency department visits and hospitalizations compared to the general population with diabetes on HDHPs [17].

\section{Food Insecurity}

Food insecurity is defined as the disruption of food intake or eating patterns stemming from several factors, one of which is economic stability. Diet is critical to the effective management of diabetes, but falls outside of the purview of what health insurance covers. Food insecurity is associated with higher A1c [18]. Possible mechanisms through which food insecurity impacts glycemic control include resource shifting, evolutionary adaptation, chronic stress or depression, low diabetes selfefficacy, or cyclical income [19]. Food insecurity in people with diabetes has been associated with poor glycemic control, limited access to necessary medications, and the use of maladaptive coping strategies for disease management [20]. Food insecurity is also associated with more frequent hypoglycemia [20]. Over time, food insecurity prevalence has been increasing in those with diabetes, with higher prevalence in households of lower socioeconomic status, and in households with people of minority racial/ethnic backgrounds [20].

Neighborhood conditions can also impact access to food supporting an optimal diet for diabetes management. Nearly 23.5 million people in the U.S. live in a food desert, defined as a low-income area that is farther than 1 mile to the nearest large grocery store [21]. Food deserts frequently consist of areas with high rates of obesity and chronic, diet-related diseases [22]; however, food retail is only one component of how the food environment impacts health. Berkowitz et al. (2018) have shown that that individual-level factors, such as food insecurity, explained substantially more of the variation in HbA1c than census tract-level factors, such as low physical food access [23].

\section{Education and Literacy}

Educational attainment and health literacy impact poor diabetes control through its influence on the ability to carry out diabetes self-management tasks. In a nationally representative sample of adults in South Korea, Kim et al. (2016) showed that attending diabetes education was positively associated with optimal glycemic control among patients with more than a high school education but was negatively associated with control among those with less than middle school education 
[24]. Mortality risks among those with uncontrolled diabetes through elevated $\mathrm{HbAlc}$ are also significantly greater in lower-educated adults than higher-educated adults [25]. Given the complexity of diabetes self-management regimens, greater educational attainment may facilitate the associated cognitive and decisional-making complexity of self-management. Lower educational attainment is also associated with lower health literacy, defined as a lack of the capacity to obtain, process, and understand basic health information and services needed to make appropriate health decisions [26, 27]. The risk of complications from diabetes is higher among patients with low health literacy [27]. Among people with type 2 diabetes, inadequate health literacy is independently associated with worse glycemic control, higher rates of retinopathy, and lower self-rated health $[28,29]$.

\section{Access to Quality Health Care}

Among the insured, insurance often provides entry into health care delivery systems. However, health services as a dimension of access can impact poor diabetes outcomes. Lack of coordinated delivery of care has been shown to adversely impact chronic disease outcomes, including diabetes outcomes [30]. Chronic care models of care delivery that aim to provide health system resources, self-management support, decision support, delivery system design, clinical information systems, and community resources and policies have been shown to reduce diabetes-related complications and all-cause mortality, microvascular complications, and urgent health care utilization, and improved glycemic control compared to delivery of care that do not utilize these approaches [31]. For example, the composition of the care team impacts diabetes control. Inclusion of multidisciplinary care team and inclusion of a pharmacist on the care team have both shown reductions in HbA1c in primary care settings [32,33]. Finally, proactive approaches using registries and the electronic health record to provide tailored outreach, decision support, and personalized feedback to diabetes patients at risk for poor outcomes, also improve diabetes outcomes and disparities [34].

A large body of evidence demonstrates that race and ethnicity remain significant predictors of the quality of health care received by patients [35]. For patients with diabetes, similar associations are seen with implications for diabetes outcomes. Hooks-Anderson et al. showed that being African American independently increased the likelihood of referral for diabetes education in patients with prediabetes and diabetes, after adjusting for patient comorbidities and risk factors [36]. Within the general population with diabetes using data from the Behavioral Risk Factor Surveillance System, Peek and colleagues showed that self-reported racial/ethnic discrimination in health care was associated with worse diabetes care and more diabetes complications, but not self-care behaviors [37]. Within a sample of American Indian women with diabetes, two-thirds reported experiencing racial discrimination in their health care experience, and those reporting perceived discrimination completed fewer diabetes services [38]. However, among 10,000 patients in a diabetes registry from a large integrated health system, there was no evidence that patient-reported health care discrimination was associated with less medication intensification, but discrimination could still be associated with other aspects of care [39].

\section{Neighborhood and Built Environment}

Neighborhood conditions can adversely impact diabetes outcomes. From geo-linked electronic health records of African American patients in network of federally qualified health centers in Philadelphia, PA, Le-Scherban and colleagues found that poor diabetes was more common in highly segregated neighborhoods (i.e., high proportion of African American residents relative to the mean for Philadelphia) [40]. Multiple studies demonstrate a link between neighborhood disadvantage and poor diabetes control [41, 42]. In a large longitudinal study of adults in New York with diabetes, Tabei et al. found that more advantaged socioeconomic conditions, greater ratio of healthy food outlets to unhealthy food outlets, and residential walkability were associated with increased glycemic control [41]. Further, individuals who lived continuously in the most advantaged residential areas took less time to achieve glycemic control compared with the individuals who lived continuously in the least advantaged residential areas, and moving from more advantaged residential areas to less advantaged residential areas was related to worsening diabetes control [41]. In a review on social order in diabetes, Steve et al. also conceptualize and demonstrate that signs of physical disorder within the built environment (e.g., dilapidated housing, few recreational spaces, broken glass on the ground) are associated with unhealthy behaviors (e.g., physical inactivity, poor dietary habits) and poor health outcomes (e.g., poor diabetes control) [43]. More studies are needed to assess the association between elements of physical disorder and diabetes control.

There is some evidence that housing has an impact on diabetes outcomes. Compared with those with more secure housing, the odds of emergency department visits or hospitalizations for those with diabetes were increased more than fivefold among those characterized by not having enough money to pay rent, staying at places where they do not pay rent, and moving frequently [44]. Qualitative interviews among low-income people transitioning into rent-assisted housing showed that rental assistance facilitated environmental control that supported diabetes routines. By making housing more affordable, rental assistance also improved some participants' ability to afford diabetes-related expenses and 
mitigated health-demoting financial stress. Additionally, for some participants, rental assistance provided residential stability that facilitated access to health-promoting local social support [45].

\section{Social and Community Context}

Poor diabetes outcomes have also been linked to factors associated with interpersonal interactions. Multiple studies highlight a direct and indirect relationship (via diabetes distress) between experiences of racial discrimination and microagressions and poor diabetes control [46-49]. Steve and colleagues describe potential mechanisms of this relationship, namely negative coping strategies (e.g., unhealthy eating, substance use, lack of physical activity), which may increase the risk of diabetes complications [43].

Social support is defined as the multifaceted experience that involves both formal and informal relationships, and can be categorized into emotional, tangible, informational, and companionship. In a systematic review by Strom and Egede examining the impact of social support on diabetes outcomes, they found that across studies, higher levels of social support influence more positive diabetes outcomes, including clinical outcomes. They also found that racial/ethnic minority groups exhibited a greater propensity for support from family and friends (including peer and support groups), compared with Whites, who relied more on support from the media and health care professionals [50]. Although there is robust evidence that social isolation and loneliness significantly increase risk for premature mortality, and increased morbidity and dysregulation of various biomarkers of health, such as inflammation [51], more studies are needed to assess the association between social isolation and diabetes control.

\section{Implications of COVID-19 Pandemic on Social Determinants of Poor Diabetes Outcomes}

The 2020 COVID-19 pandemic has led to drastic measures to protect population health, including government-mandated social distancing and 'shelter-in-place' across a number of states. These measures are especially critical to protecting the health of vulnerable populations such as those with diabetes. People with uncontrolled diabetes are at an increased risk of severe illness from COVID-19. 'Shelter-in-place' led to closures of large segments of the economy, and limited and/ or modified operation of essential businesses. To protect patients and families and preserve personal protective equipment, many health care delivery systems modified nonemergent care to virtual appointments and/or limited outpatient clinical operations in select locations. Such extreme measures for an unforeseen period of time to slow pandemic spread have significant long-term implications for the socioeconomic circumstances of individuals and families and diabetes self-care, with potential of differential impacts on population subgroups. While data is still emerging at the time of this writing, it is anticipated that there will be significant impact of social determinants on poor diabetes outcomes among the insured. Currently, increases in the number of uninsured adults are $39 \%$ higher than any annual increase ever recorded [52]. Four out of 10 low-income Americans are already struggling to afford enough food for their households [53]. Nearly every state has had record levels of unemployment [54]. Housing hardships have also reached unprecedented levels [55]. In April 2020, 1 in 3 Americans did not pay rent [55].

\section{Conclusion}

Despite the provision of health insurance, social determinants play a significant role in shaping diabetes outcomes. This narrative review highlights empirical evidence of social determinants such as economic instability, food insecurity, education and literacy, access to quality health care, neighborhood and the built environment, and social and community context that lead to poor diabetes outcomes. The COVID-19 pandemic has created the worst economic crisis for U.S. families since the Great Depression, and will have significant impacts on people with diabetes for the foreseeable future. This evidence points to the need for more empirical investigations to document the impact of wide array of social determinants of health on diabetes outcomes, and multilevel intervention approaches to address these determinants in the management of diabetes.

Funding This study was supported by the National Institute of Diabetes and Digestive and Kidney Diseases of the National Institutes of Health (R01 DK116715-01A1) and (P30DK092926) (Michigan Center for Diabetes and Translational Research).

\section{References}

1. Centers for Disease Control and Prevention. Diabetes Report Card 2017. Atlanta, GA: Centers for Disease Control and Prevention, US Dept of Health and Human Services; 2020.

2. Emerging Risk Factors Collaboration, Seshasai SR, Kaptoge S, Thompson A, Di Angelantonio E, Gao P, et al. Diabetes mellitus, fasting glucose, and risk of cause-specific death. N Engl J Med. 2011;364(9):829-41.

3. American Diabetes Association. Statistics about diabetes. 2020. Accessed from: https://www.diabetes.org/resources/statistics/ statistics-about-diabetes. Accessed 1 July 2020.

4. American Diabetes Association. Economic costs of diabetes in the U.S. in 2017. Diabetes Care. 2018;41(5):917-28. https://doi.org/10. 2337/dci18-0007.

5. American Diabetes Association. 2. Classification and diagnosis of diabetes: Standards of Medical Care in Diabetes-2019. Diabetes Care. 2019;42(Suppl 1):S13-28. https://doi.org/10.2337/dc19S002. 
6. Myerson R, Lu T, Peters A, Fox S, Huang E. Impact of health insurance policy on diabetes management. In: Delamater A, Marrero D, editors. Behavioral diabetes. Cham: Springer; 2020.

7. Kazemian P, Shebl FM, McCann N, Walensky RP, Wexler DJ. Evaluation of the cascade of diabetes care in the United States, 2005-2016 [published online ahead of print, 2019 Aug 12]. JAMA Intern Med. 2019;179(10):1376-85.

8. Zhang JX, Bhaumik D, Huang ES, Meltzer DO. Change in insurance status and cost-related medication non-adherence among older U.S. adults with diabetes from 2010 to 2014. J Health Med Econ. 2018;4(2):7. https://doi.org/10.21767/2471-9927.100040.

9. Zhang JX, Meltzer DO. The high cost-related medication nonadherence rate among Medicare-Medicaid dual-eligible diabetes patients. J Health Med Econ. 2016;2(2):13.

10. Healthy People 2020. Washington, DC: U.S. Department of Health and Human Services, Office of Disease Prevention and Health Promotion. Available from: https://www.healthypeople.gov/2020/ topics-objectives/topic/social-determinants-of-health. Accessed 1 July 2020 .

11. Walker RJ, Strom Williams J, Egede LE. Influence of race, ethnicity and social determinants of health on diabetes outcomes. Am J Med Sci. 2016;351(4):366-73. https://doi.org/10.1016/j.amjms. 2016.01.008

12. Breton MC, Guénette L, Amiche MA, Kayibanda JF, Grégoire JP, Moisan J. Burden of diabetes on the ability to work: a systematic review. Diabetes Care. 2013;36(3):740-9. https://doi.org/10.2337/ dc12-0354.

13. Riddle MC, Herman WH. The cost of diabetes care-an elephant in the room. Diabetes Care. 2018;41(5):929-32. https://doi.org/10. 2337/dci18-0012.

14. Cefalu WT, Dawes DE, Gavlak G, Goldman D, Herman WH, van Nuys K, et al. Insulin access and affordability working group: conclusions and recommendations [published correction appears in Diabetes Care. 2018 Aug;41(8):1831]. Diabetes Care. 2018;41(6): 1299-311. https://doi.org/10.2337/dci18-0019.

15. Hua X, Carvalho N, Tew M, Huang ES, Herman WH, Clarke P. Expenditures and prices of antihyperglycemic medications in the United States: 2002-2013. JAMA. 2016;315(13):1400-2. https:// doi.org/10.1001/jama.2016.0126.

16. Cohen RA, Zammitti EP. High-deductible health plan enrollment among adults aged 18-64 with employment-based insurance coverage. NCHS Data Brief, no 317. Hyattsville, MD: National Center for Health Statistics. 2018.

17. Wharam JF, Lu CY, Zhang F, Callahan M, Xu X, Wallace J, et al. High-deductible insurance and delay in care for the macrovascular complications of diabetes. Ann Intern Med. 2018;169(12):845-54. https://doi.org/10.7326/M17-3365.

18. Berkowitz SA, Baggett TP, Wexler DJ, Huskey KW, Wee CC. Food insecurity and metabolic control among U.S. adults with diabetes. Diabetes Care. 2013;36(10):3093-9. https://doi.org/10.2337/ dc13-0570.

19. Seligman HK, Jacobs EA, López A, Tschann J, Fernandez A. Food insecurity and glycemic control among low-income patients with type 2 diabetes. Diabetes Care. 2012;35(2):233-8. https://doi.org/ 10.2337/dc11-1627.

20. Flint KL, Davis GM, Umpierrez GE. Emerging trends and the clinical impact of food insecurity in patients with diabetes. J Diabetes. 2020;12(3):187-96. https://doi.org/10.1111/1753-0407.12992.

21. Dutko P, Ver Ploeg M, Farrigan T. Characteristics and influential factors of food deserts, ERR-140, U.S. Department of Agriculture, Economic Research Service. 2012.

22. National Research Council (US). The public health effects of food deserts: workshop summary. Washington (DC): National Academies Press (US); 2009. Summary. Available from: https:// www.ncbi.nlm.nih.gov/books/NBK208018/. Accessed 1 July 2020
23. Berkowitz SA, Karter AJ, Corbie-Smith G, Seligman HK, Ackroyd SA, Barnard LS, et al. Food insecurity, food "deserts," and glycemic control in patients with diabetes: a longitudinal analysis. Diabetes Care. 2018;41(6):1188-95. https://doi.org/10.2337/dc171981.

24. Kim SH. Educational attainment moderates the associations of diabetes education with health outcomes. Int J Nurs Pract. 2016;22(5):444-50. https://doi.org/10.1111/ijn.12454.

25. Dupre ME, Silberberg M, Willis JM, Feinglos MN. Education, glucose control, and mortality risks among U.S. older adults with diabetes. Diabetes Res Clin Pract. 2015;107(3):392-9. https://doi. org/10.1016/j.diabres.2014.12.013.

26. Institute of Medicine (US) Roundtable on Health Literacy. Innovations in health literacy research: workshop summary. Washington (DC): National Academies Press (US); 2011.

27. Al Sayah F, Majumdar SR, Williams B, Robertson S, Johnson JA. Health literacy and health outcomes in diabetes: a systematic review. J Gen Intern Med. 2013;28(3):444-52. https://doi.org/10. 1007/s11606-012-2241-z

28. Weiss BD, Hart G, McGee DL, D'Estelle S. Health status of illiterate adults: relation between literacy and health status among persons with low literacy skills. J Am Board Fam Pract. 1992;5(3): 257-64.

29. Schillinger D, Grumbach K, Piette J, Wang F, Osmond D, Daher C, et al. Association of health literacy with diabetes outcomes. JAMA. 2002;288(4):475-82. https://doi.org/10.1001/jama.288.4.475.

30. McDonald KM, Sundaram V, Bravata DM, et al. Closing the quality gap: a critical analysis of quality improvement strategies (Vol. 7: Care Coordination). Rockville (MD): Agency for Healthcare Research and Quality (US); 2007. (Technical Reviews, No. 9.7.) 2, Background: Ongoing Efforts in Care Coordination and Gaps in the Evidence Available from: https://www.ncbi.nlm.nih.gov/books/ NBK44011/. Accessed 1 July 2020.

31. Stellefson M, Dipnarine K, Stopka C. The chronic care model and diabetes management in US primary care settings: a systematic review. Prev Chronic Dis. 2013;10:E26. https://doi.org/10.5888/ pcd10.120180.

32. Benedetti R, Flock B, Pedersen S, Ahern M. Improved clinical outcomes for fee-for-service physician practices participating in a diabetes care collaborative. Jt Comm J Qual Saf. 2004;30(4):18794. https://doi.org/10.1016/s1549-3741(04)30020-1.

33. Pousinho S, Morgado M, Falcão A, Alves G. Pharmacist Interventions in the management of type 2 diabetes mellitus: a systematic review of randomized controlled trials. J Manag Care Spec Pharm. 2016;22((5):493-515. https://doi.org/10.18553/jmcp. 2016.22.5.493.

34. Schmittdiel JA, Gopalan A, Lin MW, Banerjee S, Chau CV, Adams AS. Population health management for diabetes: health care system-level approaches for improving quality and addressing disparities. Curr Diab Rep. 2017;17(5):31. https://doi.org/10.1007/ s11892-017-0858-3.

35. Institute of Medicine (US). Committee on Understanding and Eliminating Racial and Ethnic Disparities in Health Care. In: Smedley BD, Stith AY, Nelson AR, editors. Unequal treatment: confronting racial and ethnic disparities in health care. Washington (DC): National Academies Press (US); 2003.

36. Hooks-Anderson DR, Crannage EF, Salas J, Scherrer JF. Race and referral to diabetes education in primary care patients with prediabetes and diabetes. Diabetes Educ. 2015;41(3):281-9.

37. Peek ME, Wagner J, Tang H, Baker DC, Chin MH. Self-reported racial discrimination in health care and diabetes outcomes. Med Care. 2011;49(7):618-25

38. Gonzales KL, Lambert WE, Fu R, Jacob M, Harding AK. Perceived racial discrimination in health care, completion of standard diabetes services, and diabetes control among a sample of American Indian women. Diabetes Educ. 2014;40(6):747-55. 
39. Lyles CR, Karter AJ, Young BA, Spigner C, Grembowski D, Schillinger D, et al. Patient-reported racial/ethnic healthcare provider discrimination and medication intensification in the Diabetes Study of Northern California (DISTANCE). J Gen Intern Med. 2011;26(10):1138-44.

40. Lê-Scherban F, Ballester L, Castro JC, et al. Identifying neighborhood characteristics associated with diabetes and hypertension control in an urban African-American population using geo-linked electronic health records. Prev Med Rep. 2019;15:100953. Published 2019 Jul 13. https://doi.org/10.1016/j.pmedr.2019. 100953.

41. Tabaei BP, Rundle AG, Wu WY, Horowitz CR, Mayer V, Sheehan $\mathrm{DM}$, et al. Associations of residential socioeconomic, food, and built environments with glycemic control in persons with diabetes in New York City from 2007-2013. Am J Epidemiol. 2018;187(4): 736-45. https://doi.org/10.1093/aje/kwx300.

42. McDoom MM, Cooper LA, Hsu YJ, Singh A, Perin J, Thornton RLJ. Neighborhood environment characteristics and control of hypertension and diabetes in a primary care patient sample. J Gen Intern Med. 2020;35(4):1189-98. https://doi.org/10.1007/s11606020-05671-y.

43. Steve SL, Tung EL, Schlichtman JJ, Peek ME. Social disorder in adults with type 2 diabetes: building on race, place, and poverty. Curr Diab Rep. 2016;16(8):72. https://doi.org/10.1007/s11892016-0760-4

44. Berkowitz SA, Kalkhoran S, Edwards ST, Essien UR, Baggett TP. Unstable housing and diabetes-related emergency department visits and hospitalization: a nationally representative study of safety-net clinic patients. Diabetes Care. 2018;41(5):933-939. https://doi.org/ 10.2337/dc17-1812.

45. Keene DE, Henry M, Gormley C, Ndumele C. 'Then I found housing and everything changed': transitions to rent-assisted housing and diabetes self-management. Cityscape. 2018;20(2):107-18. https://doi.org/10.2307/26472170.

46. Wagner JA, Tennen H, Feinn R, Finan PH. Racial discrimination and metabolic control in women with type 2 diabetes. Ethn Dis. 2013;23(4):421-7.

47. Wagner J, Lampert R, Tennen H, Feinn R. Exposure to discrimination and heart rate variability reactivity to acute stress among women with diabetes. Stress Health. 2015;31(3):255-62. https:// doi.org/10.1002/smi.2542.

48. LeBrón AMW, Spencer M, Kieffer E, Sinco B, Palmisano G. Racial/ethnic discrimination and diabetes-related outcomes among Latinos with type 2 diabetes. J Immigr Minor Health. 2019;21(1): 105-14. https://doi.org/10.1007/s10903-018-0710-0.

49. Sittner KJ, Greenfield BL, Walls ML. Microaggressions, diabetes distress, and self-care behaviors in a sample of American Indian adults with type 2 diabetes. J Behav Med. 2018;41(1):122-9. https://doi.org/10.1007/s10865-017-9898-z.

50. Strom JL, Egede LE. The impact of social support on outcomes in adult patients with type 2 diabetes: a systematic review. Curr Diab Rep. 2012;12(6):769-81. https://doi.org/10.1007/s11892-0120317-0.

51. Holt-Lunstad J. Social isolation and health. Health Aff. 2020. https://doi.org/10.1377/hpb20200622.253235.

52. Dorn S. The covid-19 pandemic and resulting economic crash have caused the greatest health insurance losses in American history. 2020. Families USA. Accessed from: https://familiesusa.org/ resources/the-covid-19-pandemic-and-resulting-economic-crashhave-caused-the-greatest-health-insurance-losses-in-americanhistory/. Accessed 1 July 2020.

53. Wolfson JA, Leung CW. Food insecurity and COVID-19: disparities in early effects for US adults. Nutrients. 2020;12(6):E1648. Published 2020 Jun 2. https://doi.org/10.3390/nu12061648.

54. Washington Post. Nearly every state has had record levels of unemployment last month. 2020. Accessed from: https://www. washingtonpost.com/. Accessed 1 July 2020.

55. Brookings Institute. Housing hardships reach unprecedented heights during the COVID-19 pandemic. 2020. Accessed from: https://www.brookings.edu/blog/up-front/2020/06/01/housinghardships-reach-unprecedented-heights-during-the-covid-19pandemic/. Accessed 1 July 2020.

Publisher's Note Springer Nature remains neutral with regard to jurisdictional claims in published maps and institutional affiliations. 